\title{
Paraplegia
}

\section{Psychological Adjustment Following Traumatic Spinal Cord Injury: A Study Using the Psychosocial Adjustment to Illness Scale}

\author{
F.K. Judd, MD, DPM, FRANZCP, J.E. Webber DPM, FRANZCP, \\ D.J. Brown FRACP, FACRM, T.R. Norman PhD, G.D. Burrows MD, DPM, \\ FRANZCP, FRCPSYH \\ University of Melbourne, Department of Psychiatry and Spinal Injuries Unit, Austin \\ Hospital, Heidelberg, Vic 3084, Australia.
}

\begin{abstract}
Summary
Using the psychological adjustment to illness scale (PAIS) psychosocial adjustment to traumatic spinal cord injury (SCI) in 52 patients were assessed. Females and paraplegics tended to show better adjustment than males and quadriplegics. Older individuals, those with a history of depression following SCI and those with a history of alcohol and drug abuse predating SCI tended to be less well adjusted. Further studies are required to confirm the utility of the PAIS in this patient population.
\end{abstract}

Key words: Traumatic spinal cord injury, Psychosocial adjustment; The psychosocial adjustment to illness scale (PAIS).

Several studies have attempted to identify variables associated with good or poor adjustment following spinal cord injury (SCI). Methodological problems such as poor definition of adjustment, and the failure to take into account confounding variables such as concomitant head injury and pre-existing psychopathology have made these difficult to interpret. Factors suggested to predict good adjustment include young age (Kemp and Vash, 1971, Kerr and Thompson, 1972, Wilcox and Stauffer, 1972), being female (Woodrich and Patterson, 1983), pre-injury educational and occupational attainment and theoretical interest (Nickerson 1971), satisfactory pre-injury life history (Kerr and Thompson, 1972) and supportive interpersonal relationships (Kemp and Vash 1971, Kerr and Thompson, 1972) and premorbid personality traits such as high ego strength, ability to delay gratification (Roberts, 1976) and conscientiousness (Witthower et al., 1954).

The aim of the following study was to gather data about patients' adjustment to $\mathrm{SCI}$, using an instrument previously found to be a reliable and valid measure of adjustment to chronic illness in other patient populations. This paper reports the

Correspondence to: Associate Professor Fiona Judd, University of Melbourne, Department of Psychiatry, Austin Hospital, Heidelberg, Victoria 3080, Australia. 
preliminary results of the study using this instrument, i.e. The Psychosocial Adjustment to Illness Scale (PAIS) (Derogatis, 1986) in measuring the adjustment of a group of spinal cord injured patients.

\section{Subjects and methods}

The subjects were 52 patients with traumatic SCI. All had been admitted to the Spinal Injuries Unit (SIU) of the Austin Hospital within the preceding 18 months, and fulfilled the following criteria; male or female, aged 18 years and over, admitted to SIU within 24 hours of injury.

All were assessed by the Liaison Psychiatrist within 2 weeks of admission and regularly seen by the Liaison Psychiatrist/Psychologist during their admission. Patients with pre-existing psychiatric illness, organic cerebral disorder and concomitant head injury were excluded from the study.

The patients all received acute medical and rehabilitation therapy in the Austin Hospital SIU and returned to the hospital outpatient clinic for follow-up after discharge. Patients filled in the questionnaire during a routine outpatient visit between 6 to 12 months after discharge from hospital. Sociodemographic data and information concerning past psychiatric and medical history were collected at the time of initial admission to hospital. Data regarding affective disturbance during admission was collected as part of a prospective study of depression following SCI and has been reported elsewhere (Judd et al., 1989).

The 8 female and 44 male patients were aged 17 to 72 (mean $31 \cdot 8 \pm 14 \cdot 2$ ) years. Thirty one were paraplegic and 21 were quadriplegic. Twenty five were single, 23 married and 4 divorced or widowed. Examination of employment status showed there were 22 manual workers, 4 students, 9 professional persons, 5 in business, 3 in clerical work, 3 unemployed and 3 involved in home duties. Nine were prescribed anti-depressants for the treatment of a major depressive episode (DSM III) during their inpatient treatment. Otherwise, with the exception of benzodiazepines for muscle spasm and hypnotic medications, no psychotropics were prescribed.

PAIS (Derogatis and Lopez, 1983) was used to gather information about patients' opinions on their own adjustment. The PAIS is composed of seven sections; Section 1-Health Care Orientation: 'addresses the nature of the respondent's health care posture, and whether it will function to promote a positive or negative adjustment to the illness and its treatment'; Section II-Vocational Environment: 'is designed to reflect the impact that a medical disorder may have on vocational (work, school, home) adjustment'; Section III-Domestic Environment: 'is oriented towards illness-induced difficulties that arise primarily in the house or family environment'; Section IV-Sexual Relationships: 'is designed to provide a measure of any changes in the quality of sexual functioning or relationship associated with the patient's illness or sequelae of illness', Section VExtended Family Relationships: 'devoted to measuring any description or derangement in relationships with the extended family constellation that arise associated with the illness experience'; Section VI-Social Environment: 'reflects the status of the patient's current social and leisure time activities and the extent to which the patient has suffered impairment or constriction of these activities as a result of the current illness and/or its residual effects'; Section VII - Psychological Distress: 'designed to measure dysphoric thoughts and feelings that accompany the 
patients' disorder or are a direct result of the illness and its sequelae'. The Self Report (SR) version was used in which each item is composed of four statements used as a 4-point scale and scored from 0--no disturbance, to 3-marked disturbance. The total score of the PAIS-SR (46 items) ranges from 0 to 138 . Thus, the lower scores indicate better adjustment and higher scores indicate worse adjustment.

Two physicians independently rated the patients' adjustment, i.e. achievements related to expected rehabilitation outcome which takes into account physical health, mobility, and rehabilitation goals regarding activities of daily living and psychological health. Their ratings were then compared and a consensual score obtained.

\section{Results}

A wide range of total PAIS scores was found, some patients reporting very good adjustment on the PAIS while others reported very poor adjustment. The mean for the whole group was $39 \cdot 6$ (SD 13.5), with various sections contributing differently to the total score (Table 1). Most dysfunction was reported in vocational environment, followed by domestic and then social environment.

The inter-relationship between the scores on the sections of the PAIS were examined by Spearman rank correlation analysis. Only weak to moderate correlations were found between subscales (Table II), while stronger coefficients were

Table I PAIS scores for total group

\begin{tabular}{llrl}
\hline PAIS section & Mean & SD \\
& & \\
I Health care orientation & $7 \cdot 00$ & $2 \cdot 88$ \\
II & Vocational environment & $8 \cdot 14$ & 3.99 \\
III Domestic environment & $7 \cdot 40$ & 2.90 \\
IV Sexual relationships & 5.69 & 4.43 \\
V Extended family relationships & $1 \cdot 75$ & $2 \cdot 09$ \\
VI Social environment & 5.90 & 4.38 \\
VII Psychological distress & 4.49 & 3.38 \\
& & \\
Total & 39.59 & 13.53 \\
\hline
\end{tabular}

Table II Correlations among domain scores and total score

\begin{tabular}{|c|c|c|c|c|c|c|c|c|}
\hline & & I & II & III & IV & V & VI & VII \\
\hline Health care orientation & I & & & & & & & \\
\hline Vocational environment & II & $\cdot 214$ & & & & & & \\
\hline Domestic environment & III & $\cdot 178$ & $\cdot 236$ & & & & & \\
\hline Sexual relationships & IV & $\cdot 206$ & .069 & $\cdot 479^{\star}$ & & & & \\
\hline Extended family relationships & V & $\cdot 188$ & $-\cdot 234$ & $\cdot 321+$ & $\cdot 415^{\star}$ & & & \\
\hline Social environment & VI & .053 & $-\cdot 267$ & $\cdot 278+$ & 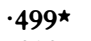 & $\cdot 479 \star$ & & \\
\hline Psychological distress & VII & .081 & -.093 & $\cdot 112$ & $\cdot 303+$ & $\cdot 499 \star$ & $\cdot 311+$ & \\
\hline Total & & $\cdot 386^{\star}$ & $\cdot 212$ & $\cdot 587^{\star}$ & $\cdot 820^{\star}$ & $\cdot 596^{\star}$ & $.601^{\star}$ & $\cdot 493$ \\
\hline
\end{tabular}

$\star \mathrm{P}<\cdot 005$

$+\mathrm{P}<\cdot 05$ 
found for subscales III, IV, V and VI with total score. This configuration suggests the domains measured are relatively specific and unique in their representation of the multi-dimensional construct of adjustment.

\section{PAIS scores and physician assessment}

The physicians' assessments of adjustment $(1=$ very good, $2=\operatorname{good}, 3=$ fair, $4=$ bad) were compared with PAIS scores. Three were rated as very good, 26 as good, 16 as fair and 3 as poor adjusters. The 3 rated as poor adjusters were rated as third and fourth worst and second best adjusted by PAIS scores. The patients rated as very good and good by the clinicians were grouped together as 'good' and those rated as fair and bad were grouped together as 'poor'. Differences in PAIS domain and total scores were then compared using ANOVA and the clinician's global impression (good vs poor) as a criterion variable. A significant difference was found for domains IV (sexual relationships), V (extended family relationships), VI (social environment) and VII (psychological distress) $(\mathrm{p}<0.05)$.

\section{Good and poor adjusters}

Analysis of PAIS total scores by sex showed females were better adjusted than males $(t=2.94 p<\cdot 05)$ (Table III). While females scored lower on each domain, only on social environment (Section VI) did the difference achieve statistical significance $(\mathrm{p}<\cdot 001)$.

Comparison of PAIS total score by age ( $<30$ years, 30 to 50 years, $>50$ years) showed no significant difference (ANOVA). The age group $<30$ years and $30-50$ years had similar scores (39.6 and $36 \cdot 3$ respectively) while the older group had a higher score $(48 \cdot 0)$. Analysis of PAIS scores by diagnosis showed a trend for paraplegics overall to be better adjusted than quadriplegics $(t=1 \cdot 74, p=0.089)$ (Table IV). While scores on domains such as vocational and social environment, which might be expected to be more severely disrupted for quadriplegics, were lower in

Table III Influence of sex on pais scores

\begin{tabular}{|c|c|c|c|c|c|}
\hline \multirow[b]{2}{*}{ Total } & \multicolumn{2}{|c|}{ Male } & \multicolumn{2}{|c|}{ Female } & \multirow{2}{*}{$\frac{\text { Sig }}{.01}$} \\
\hline & $\overline{\mathbf{x}}$ & $41 \cdot 49$ & $\overline{\mathbf{x}}$ & $29 \cdot 38$ & \\
\hline & SD & $13 \cdot 32$ & SD & $10 \cdot 13$ & \\
\hline \multirow[t]{2}{*}{ I } & $\overline{\mathbf{x}}$ & $7 \cdot 20$ & $\overline{\mathbf{x}}$ & $5 \cdot 88$ & NS \\
\hline & $\mathrm{SD}$ & $2 \cdot 92$ & SD & $2 \cdot 47$ & \\
\hline \multirow[t]{2}{*}{ II } & $\overline{\mathbf{x}}$ & $8 \cdot 56$ & $\overline{\mathbf{x}}$ & $6 \cdot 00$ & NS \\
\hline & SD & $4 \cdot 09$ & SD & $2 \cdot 72$ & \\
\hline \multirow[t]{2}{*}{ III } & $\overline{\mathbf{x}}$ & $7 \cdot 56$ & $\overline{\mathbf{x}}$ & $6 \cdot 50$ & NS \\
\hline & SD & 3.06 & SD & $1 \cdot 69$ & \\
\hline \multirow[t]{2}{*}{ IV } & $\overline{\mathbf{x}}$ & $6 \cdot 02$ & $\overline{\mathbf{x}}$ & $3 \cdot 88$ & NS \\
\hline & SD & $4 \cdot 13$ & SD & $5 \cdot 79$ & \\
\hline \multirow[t]{2}{*}{ V } & $\overline{\mathbf{x}}$ & $1 \cdot 91$ & $\overline{\mathbf{x}}$ & $\cdot 88$ & NS \\
\hline & SD & $2 \cdot 21$ & SD & .99 & \\
\hline \multirow[t]{2}{*}{ VI } & $\overline{\mathbf{x}}$ & $6 \cdot 51$ & $\overline{\mathbf{x}}$ & $2 \cdot 63$ & $\cdot 001$ \\
\hline & SD & $4 \cdot 42$ & SD & $2 \cdot 26$ & \\
\hline \multirow[t]{2}{*}{ VII } & $\overline{\mathbf{x}}$ & $4 \cdot 65$ & $\overline{\mathbf{x}}$ & $3 \cdot 63$ & NS \\
\hline & SD & $3 \cdot 48$ & SD & $2 \cdot 83$ & \\
\hline
\end{tabular}


Table IV Influence of diagnosis on pais scores

\begin{tabular}{|c|c|c|c|c|c|}
\hline \multirow{3}{*}{ Total } & \multicolumn{2}{|c|}{ Paraplegic } & \multicolumn{2}{|c|}{ Quadriplegic } & \multirow{2}{*}{$\begin{array}{c}\text { Sig } \\
\cdot 089\end{array}$} \\
\hline & $\overline{\mathbf{x}}$ & $36 \cdot 90$ & $\overline{\mathbf{x}}$ & 43.43 & \\
\hline & SD & $13 \cdot 41$ & SD & $13 \cdot 07$ & \\
\hline \multirow[t]{2}{*}{ I } & $\overline{\mathbf{x}}$ & 6.94 & $\overline{\mathbf{x}}$ & $7 \cdot 10$ & NS \\
\hline & SD & $3 \cdot 20$ & SD & $2 \cdot 39$ & \\
\hline \multirow[t]{2}{*}{ II } & $\overline{\mathbf{x}}$ & $7 \cdot 79$ & $\overline{\mathbf{x}}$ & $8 \cdot 65$ & NS \\
\hline & SD & $3 \cdot 83$ & $\mathrm{SD}$ & $4 \cdot 28$ & \\
\hline \multirow[t]{2}{*}{ III } & $\overline{\mathbf{x}}$ & $7 \cdot 10$ & $\overline{\mathbf{x}}$ & $7 \cdot 86$ & NS \\
\hline & SD & $2 \cdot 55$ & SD & $3 \cdot 38$ & \\
\hline \multirow[t]{2}{*}{ IV } & $\overline{\mathbf{x}}$ & $4 \cdot 84$ & $\overline{\mathbf{x}}$ & 6.95 & NS \\
\hline & SD & $3 \cdot 78$ & SD & $5 \cdot 08$ & \\
\hline \multirow[t]{2}{*}{ V } & $\overline{\mathbf{x}}$ & $1 \cdot 80$ & $\overline{\mathbf{x}}$ & $1 \cdot 67$ & NS \\
\hline & SD & $1 \cdot 73$ & SD & $2 \cdot 58$ & \\
\hline \multirow[t]{2}{*}{ VI } & $\overline{\mathbf{x}}$ & $5 \cdot 00$ & $\overline{\mathbf{x}}$ & $7 \cdot 19$ & NS \\
\hline & SD & $3 \cdot 76$ & SD & 4.95 & \\
\hline VII & $\begin{array}{c}\overline{\mathbf{x}} \\
\text { SD }\end{array}$ & $\begin{array}{l}4.53 \\
3 \cdot 22\end{array}$ & $\begin{array}{c}\overline{\mathbf{x}} \\
\text { SD }\end{array}$ & $\begin{array}{l}4.43 \\
3.67\end{array}$ & NS \\
\hline
\end{tabular}

paraplegics, the differences were not statistically significant. Psychological distress scores were similar in both groups.

Analysis by marital status revealed no significant difference (ANOVA) (single $\overline{\mathrm{x}}=39 \cdot 7$, married $\overline{\mathrm{x}}=39 \cdot 7$, widowed/divorced $\overline{\mathrm{x}}=38 \cdot 3$ ). While there was a trend for those who had been treated for depression to be less well adjusted than those who had not been depressed $(\overline{\mathrm{x}} 43 \cdot 4 \pm 13 \cdot 7$ of $38 \cdot 3 \pm 13 \cdot 5)$ the difference was not statistically significant ( $t$ test $P>0 \cdot 1$ ). Similarly, there was a trend for those with a past history of alcohol or drug abuse to be less well adjusted $(\overline{\mathrm{x}} 46 \cdot 4 \pm 10 \cdot 8)$ than those without such a history $(\overline{\mathrm{x}} 37.9 \pm 13.9)$ the difference did not quite reach statistical significance $(t=2 \cdot 80, p=0.053)$.

\section{Discussion}

The main aim of the present study was to gather data about adjustment to spinal cord injury and to assess the utility of the PAIS in this population. The distribution of the total scores on the PAIS suggests that the scale is able to distinguish between levels of adjustment. Further, the general agreement between PAIS scores and physicians' assessment of adjustment tends to lend weight to the idea that this scale is valid.

Consistent with the original report on the PAIS the correlations between subscales were generally low, but were well correlated with the total score. The strongest relationships between scales were found between sexual relationships and domestic environment, sexual relationships and social environment, psychological distress and extended family relationships. Of interest, sexual relationships, domestic environment, social environment and extended family relationships were strongly correlated with overall adjustment, consistent with previous findings that supportive interpersonal relationships are associated with good adjustment. Contrary to previous suggestions that pre-injury educational and occupational attainment were predictors of good adjustment, vocational environment (Section II) was only poorly correlated with total PAIS score. This may be partly explained 
by the employment distribution of the group ( $50 \%$ manual work or unemployed at time of injury).

As suggested by previous studies, females appeared to show better adjustment than males. However, given the small number of women in the group, this finding must be interpreted with caution. The trend for paraplegic patients to show better adjustment is consistent with previous studies but requires further examination. As we have previously found in a study of depression following SCI (Judd et al., 1989), rather than confirming that degree of disability is important, the suggested difference noted here may highlight the need to consider other variables such as pre-injury personality and coping mechanisms as important predictors of adjustment.

The trend for older individuals to show poorer adjustment also warrants further investigation. Perhaps, older individuals are less able to develop new coping mechanisms and ways of maintaining self esteem. Also, those caring for older patients may have greater difficulties coping and more personal health problems which exacerbate the problems of adjustment.

The finding that those with history of major depressive episode developing after SCI tended to be less well adjusted was not surprising. These individuals had previously been shown to have more interpersonal and pesronality factors predictive of difficulties coping (Judd et al., 1989). Likewise a history of alcohol or drug abuse is frequently an indicator of poor coping ability and thus the association of this with poor adjustment is not unexpected.

The finding of lower scores on PAIS domains IV, V, VI, VII in those patients considered to be better adjusted by the clinician's global assessment may be interpreted in several ways. Firstly, the items in these domains may be more relevant than those in the other domains for patients with SCI. For example, vocational environment (Domain II) may be expected to be disrupted in the majority of patients, irrespective of level of adjustment. Secondly, the findings may reflect the pattern of care in the ward. Education, active rehabilitation and close medical followup are offered to all patients in the unit. All patients in this study had previously participated in a prospective study of depression following SCI, and had been seen regularly by the liaison psychiatrist or psychologist in the SIU. These factors may account for the lack of differences between groups on Domain I. Thirdly, the present study is of only a small group of patients.

Further studies using larger numbers of patients are required to further assess the utility of the PAIS in this group of patients. In particular, attention must be directed to determining which scales (or items of each scale) are most useful. Comparison with patients from other units will help to determine whether our findings regarding the utility of the various domains reflect the type of care in our unit, or rather the lack of sensitivity of certain items in assessing outcome in these patients.

Using an instrument such as this as an outcome measure, the role of variables such as personality, defence style, coping mechanisms, family interaction and many others in facilitating or impeding adjustment following SCI maybe studied.

\section{Acknowledgements}

The authors gratefully acknowledge the assistance of Dr. G.H. Ungar, Dr. J. Gelb and staff in the outpatient's department, Austin Hospital in the collection of the data. 


\section{References}

Derogatis LR 1986 The Psychosocial Adjustment to Illness Scale (PAIS), Fournal of Psychosomatic Research 30:77-91.

Derogatis LR, LoPEZ M 1983 Psychosocial Adjustment to Illness Scale. (PAIS \& PAIS-SR) Scoring, Procedures and Administration Manual I., Baltimore, Clinical Psychomatic Research.

Judd FK, Stone J, WebBer JE, Brown DJ, Burrows GD 1989 Depression following Spinal Cord Injury: A Prospective In-patient study. B f Psychiatry 154:668-671.

KeMP G, VASH C 1971 Productivity after injury in a sample of spinal cord injured persons. A pilot study. F Chronic Disease 24:259-275.

KERR W, THOMPSON M 1972 Acceptance of disability of sudden onset in paraplegia. Paraplegia 10:94-102.

NiCKERSON E 1971 Some correlates of adjustment by paraplegics. Percept Mot Skills 32:11-23.

ROBERTS AH 1976 Spinal cord injury-Some psychological considerations. Minn Med 55:1115-1117.

Wilcox N, STAUFFER E 1972 Follow-up of 423 consecutive patients admitted to the spinal cord centre Rancho Los Amigos Hospital, 1 January to 31 December 1967. Paraplegia 10:115-122.

WitThower E, Gingras G, MEgLER L, WIDGOR B, LEPINE A 1954 A combined psychosocial study of spinal cord lessons. Can Med Asso f 71:109-15.

WOODRICH F, PATTERSON JB 1983 Variables related to acceptance of disability in persons with spinal cord injuries. $\mathcal{F}$ Rehabilitation 49:26-30. 